\title{
A construção da argumentação na carta-testamento de Getúlio Vargas
}

\author{
José Olavo da Silva Garantizado Júnior ${ }^{l}$
}

\begin{abstract}
The construction of the argument is one of the more academic topics discussed by diverse areas of knowledge. In this context, this study aims to analyze how is the argument in the Letter Testament of President Getúlio Vargas. For this, our theoretical basis will Guarantee Junior (2015), which analyzed the argument considering external aspects of the text (External elements of the argument), textual aspects (Generic Component and Component Sequential) and rhetorical aspects (Component Rhetorical). In terms of methodology, our research will have documentary character, since we analyze the letter officially released by the president's death the time of the authorities to the press. The results show that the construction of the President's text argument constitutes a strong influence of external elements of the argument, especially the time and the specific communicative situation, which ultimately interferes with the production of its kind letter and sequential structure. Moreover, the president's image in Rhetorical component, is built from positive projections of its ethos, always laying the blame for his death to the time of social pressure experienced in the country.
\end{abstract}

Keywords: Argumentation; Getúlio Vargas; Argumentation model.

Resumo: A construção da argumentação é um dos tópicos acadêmicos mais discutidos por diversificadas áreas do conhecimento. Nesse contexto, o presente trabalho tem como objetivo analisar como se constitui a argumentação na Carta-Testamento do presidente Getúlio Vargas. Para isso, nossa base teórica será Garantizado Júnior (2015), que analisou a argumentação considerando-se aspetos externos ao texto (Elementos Externos da argumentação), aspectos textuais (Componente Genérico e Componente Sequencial) e aspectos retóricos (Componente Retórico). Em termos metodológicos, nossa pesquisa terá caráter documental, uma vez que analisaremos a carta divulgada oficialmente pelas autoridades da época da morte do presidente para a imprensa. Os resultados apontam que a construção da argumentação do texto do presidente se constitui de uma forte influência dos elementos externos da argumentação, principalmente a época e a situação comunicativa específica, o que acaba interferindo na produção do gênero carta e na estrutura sequencial. Além disso, a imagem do presidente, no Componente Retórico, constrói-se a partir de projeções positivas de seu ethos, sempre impondo a culpa de sua morte para o momento de pressão social vivenciado no país.

Palavras-chave: Argumentação; Getúlio Vargas; Modelo de Argumentação.

1 Professor Adjunto da Universidade da Integração Internacional da Lusofonia Afro-Brasileira (UNILAB) 
O mês de agosto de 1954 é um dos mais conflituosos da História do Brasil. O presidente Getúlio Vargas estava em meio a uma enorme crise política, que o distanciava consideravelmente do Congresso, devido à maneira como o estadista estava direcionando as ações governamentais. O aumento de $100 \%$ do salário mínimo como medida populista e a instauração da Petrobrás e da Eletrobrás, empresas genuinamente brasileiras e oriundas do capital estatal, sem a participação efetiva do Congresso nas decisões e das forças políticas do capital estrangeiro, propiciou um clima de muitas incertezas entre o presidente e o mercado financeiro internacional. Aos poucos, a autoridade e a legitimidade do Governo Vargas estava sendo questionada. A oposição iniciou fortes ações de bastidores contra a figura do presidente que, antes era intocável, e no mês de agosto do referido ano, estava ameaçada.

$\mathrm{O}$ atentado contra Carlos Lacerda, na madrugada do dia 05 de agosto, o famoso atentado da Rua Toneleros, em que as investigações induziam para uma tentativa premeditada contra o maior opositor de Vargas e que fora "planejada" pelo chefe da guarda-pessoal do presidente, o ex-policial Gregório Fortunato, foi o estopim para uma forte pressão contra o presidente. O governo estava enfraquecido e os grupos de oposição "jogavam o povo contra o presidente". No dia 24 de agosto, a população brasileira recebia atônita a notícia de que Vargas, muito pressionado, havia cometido suicídio. Antes de cometê-lo, o estadista deixou uma Carta-Testamento, um dos principais documentos do Brasil até hoje, em que se tinham algumas explicações dos motivos reais para o fato. Após a leitura do documento pela imprensa, o movimento contrário ao governo fora rapidamente substituído por uma força favorável à figura do presidente populista. A ação suicida de Getúlio representou um "duro golpe" nos planos dos opositores que, pressionados, começaram a ser "responsabilizados" pela morte do ilustre estadista.

Como se pode notar, o documento de Vargas tornou-se um objeto valioso de estudo para as mais diversificadas áreas do conhecimento, pois o texto constitui-se de um importante instrumento de interpretação política, econômica e social. Para nós, a Carta-Testamento é, também, um objeto de estudo para analistas do texto e do discurso. Ciente disso, esse trabalho se alicerçou a partir da necessidade de estudar o documento oficial sob um prisma textual e retórico, tendo como princípio de análise o processo de construção da argumentação no texto.

Com efeito, para analisar esse objeto de estudo, utilizaremos como base teórica a proposta de descrição e de investigação da argumentação que desenvolvemos em nossa tese de doutoramento (GARANTIZADO JÚNIOR, 2015). Achamos oportuna a aplicação da abordagem pela qual elaboramos, uma vez que, naquela oportunidade, investigamos como a argumentação também pode sofrer interferências de aspectos externos ao texto, o que denominamos de Elementos Externos ao Texto. No contexto de escritura da carta, os impactos da época e da situação comunicativa em si são, com certeza, primordiais para se entender como o Locutor quer persuadir seu interlocutor.

Nesse sentido, nosso trabalho é relevante para os estudos das Letras em geral, assim como para as aeras afins, porque aplicaremos um modelo analítico da argumentação recém desenvolvido, podendo fazer conjecturas sobre as categorias exequíveis em diversificados tipos de práticas discursivas. Além disso, em analisarmos um documento de tamanha importância para as áreas de História, Sociologia, Filosofia e Ciências Políticas, estamos promovendo uma interface entre o discurso político e as estratégias de persuasão usadas pelos seus Locutores no que tange à argumentação. 


\section{O modelo teórico da argumentação sob um olhar textual e retórico}

Desde Aristóteles até o início do século XXI, as maneiras de lidar com os fenômenos argumentativos (ou pelo menos os que envolviam a persuasão) estiveram sempre limitados, ora a aspectos eminentemente retóricos, ora a aspectos de natureza eminentemente textual. Poucos foram os trabalhos que buscaram uma correlação entre essas perspectivas teóricas. Trabalhos como os de Patrick Chareaudeau (1983, 1992, 1994) e de Rosalice Pinto (2010) visaram trazer para as análises textuais e discursivas elementos externos ao texto e ao discurso. Merece destaque o trabalho dessa última autora que, a partir da análise de textos verbais e não verbais, desenvolveu um modelo argumentativo com categorias da Linguística do Texto e da Análise do Discurso.

Apesar de o Brasil ser um dos países com grande quantidade de trabalhos sobre argumentação em diversificadas áreas do conhecimento, percebemos, a partir da leitura de Pinto (2010), que são poucas as pesquisas que consideraram os aspectos externos ao texto como elementos que pudessem ser sistematizados e explorados em uma análise do processo argumentativo. Assim, a partir da evidência nítida dessa lacuna nos estudos de argumentação, elaboramos um modelo analítico desse fenômeno que pudesse ser desenvolvido, levando-se em consideração aspectos externos ao texto, assim como elementos textuais e retóricos. Para ilustrarmos de maneira mais didática nosso pensamento, observemos o esquema a seguir, que sistematiza as categorias usadas em nossa abordagem:

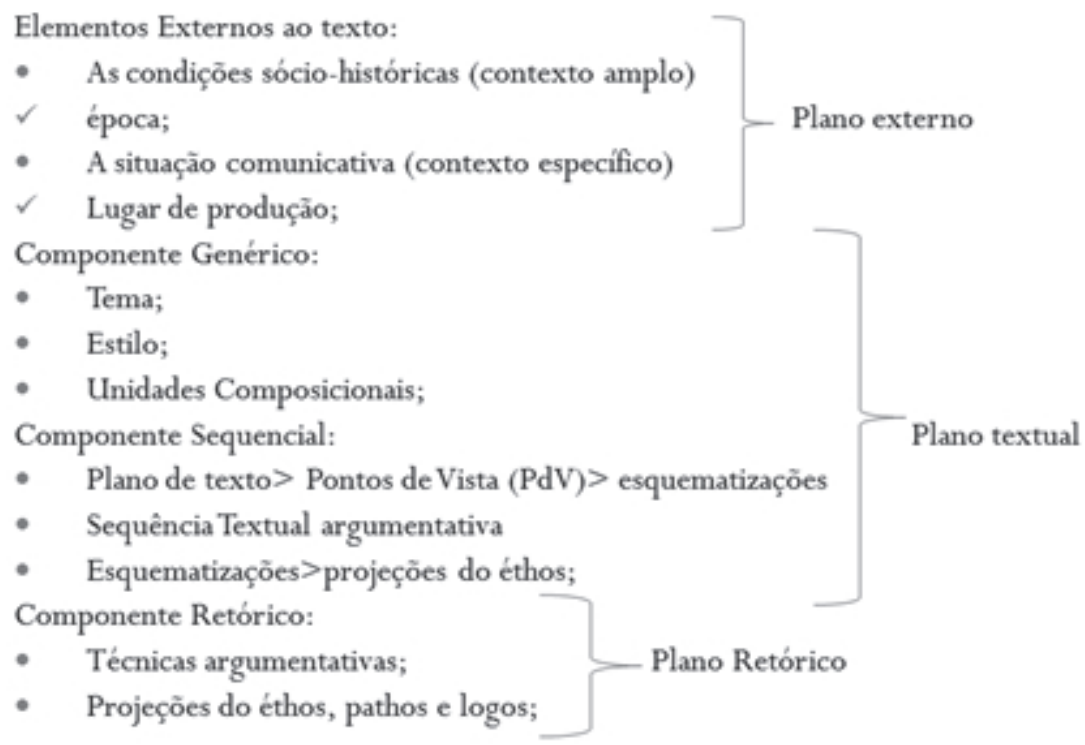

Esquema 1- Representação do modelo desenvolvido por Garantizado Júnior (2015)

Como podemos perceber no esquema 1, nossa proposta de argumentação possui três planos de investigação e descrição do processo argumentativo. Importante que se diga que, em nossa abordagem, o pesquisador/analista pode, sem prejuízo de descrição e percepção dos fenômenos a serem estudados, optar em analisar apenas um dos planos, dependendo de seu objeto de investigação. Nesse contexto, defendemos que o plano externo ao texto, 
o plano textual e o plano retórico da argumentação podem ser estudados de forma inter-relacionados, aplicando-os em uma só pesquisa analítica, mas que também podem ser analisados isoladamente, dependendo dos propósitos do pesquisador e de seu objeto de estudo.

Nesse sentido, no plano externo, temos os Elementos Externos ao texto, que se dividem em duas partes: as condições sócio-históricas (contexto amplo da argumentação) e a situação comunicativa (contexto específico da argumentação). Esse plano é importante por situar o Locutor na época e no lugar de produção de seu texto, o que acaba contribuindo para a constituição do plano textual, pois os elementos externos proporcionam coerções na estrutura composicional do gênero. No plano textual, temos dois importantes Componentes de nossa abordagem: a) Componente Genérico (BAKHTIN, 1997), que sofre coerções dos aspectos externos e é dividido em tema, estilo e as unidades composicionais e o b) Componente Sequencial (ADAM, 1992, 2008), que é dividido em plano de texto, sequência textual argumentativa e formação de esquematizações. Por último, no plano retórico, teremos o Componente Retórico, formado a partir das técnicas argumentativas (PERELMAN; TYTECA, 1996) em que os Locutores tentam provar a veracidade de suas teses, assim como as projeções de suas imagens na prática discursiva (AMOSSY, 2011). Ciente disso,passemos para a explanação de como cada categoria é considerada teoricamente em nossa abordagem e, em seguida, analisaremos, na próxima seção, a carta-testamento de Getúlio Vargas sob o prisma de nossa proposta.

Defendemos que o Locutor busca, em diversificadas situações comunicativas, persuadir um interlocutor. Para isso, aquele se vale de uma série de procedimentos linguísticos pelas quais, quase sempre, mesmo sem perceber, ele usa e, do ponto de vista argumentativo, têm como função principal legitimar a argumentação, uma vez que não basta que um sujeito emita somente proposições sobre o que está sendo discutido, é preciso que estas sejam provadas (ou até contestadas), sempre objetivando apresentá-las como verdadeiras.

Com efeito, buscamos aliar aspectos eminentemente textuais e retóricos com outros fenômenos que não podem de maneira alguma de serem desprezados: o contexto de produção do texto. Para tal, consideraremos a argumentação como um fenômeno que pode ser descrito do ponto de vista textual e retórico, levando-se em conta uma série de fatores externos que exercem coerções sobre o Locutor no momento em que este busca persuadir o seu auditório. Para esses aspectos, denominados de Elementos Externos da argumentação e se constituiriam em dois níveis: as condições sociais de produção (contexto amplo) e a situação comunicativa (contexto específico).

O Locutor, quando profere seu texto, está inserido em uma realidade social e histórica que o faz usar estratégias argumentativas, segundo a época em que o texto será realizado. Não se pode deixar de considerar também que, muitas vezes, o texto pode ser usado em realidades históricas diferentes, com objetivos diferentes, o que nos possibilita considerar que um texto pode estar inserido em diferentes contextos históricos, caso o Locutor necessite dele, para embasar uma estratégia argumentativa. Sobre isso, filiamo-nos ao mesmo pensamento de que

um analista que busque estudar a argumentação sob um prisma textual e retórico, ou apenas sob uma das abordagens (apenas textual ou apenas retórica), deve levar em consideração em suas análises o contexto sócio-histórico em que o texto foi produzido e, se necessário, pode até comparar épocas diferentes, já que, muitas vezes, o Locutor se vale desses recursos comparativos de épocas para construir sua base de argumentos. Essa conclusão é óbvia, pois não podemos nos separar de nossa época. Esse argumento é o que nos fez propor que, sempre, o Locutor necessita saber qual o contexto em que está inserido (GARANTIZADO JÚNIOR, 2015, p. 113). 
Na verdade, é evidente a importância que o contexto amplo, chamado de época sócio -histórica, pode possuir (e até interferir) na constituição dos argumentos a serem apresentados pelo Locutor. Achamos oportuno considerar esse contexto mais amplo de produção do ato argumentativo por sabermos que, de certa maneira, um texto carrega em si uma argumentação que se processa, desde o momento de produção, quando o Locutor prepara o seu discurso, até o momento da realização, quando o texto pode (ou não) persuadir o auditório. Desse modo, consideramos que a época em que o texto está sendo realizado integraria um dos elementos do contexto sócio-histórico do qual o produtor se valeria para buscar a persuasão. Devemos deixar claro que, de alguma maneira, o Locutor usufrui de alguns conhecimentos compartilhados da época em que está inserido para tentar persuadir seu público. Isso não significa que um texto de um período anterior ao momento em que o Locutor está vivendo seja interpretado como algo deslocado ou sem argumentatividade. $\mathrm{Na}$ verdade, defendemos que, de alguma maneira, consciente ou inconsciente, o Locutor sofre certas coerções que o faz saber que tipo de estratégia argumentativa pode usar para poder persuadir seu auditório.

Outro aspecto a ser considerado é a situação comunicativa em que o Locutor está inserido, que também contribui para a argumentação. Esse conceito, inclusive, fora tratado por Maingueneau (2004) como momento de realização empírico. Entretanto, não consideramos a situação comunicativa como apenas o espaço em que ocorre a produção do texto, mas uma série de elementos do momento de produção, sempre amparados pelo contexto mais amplo de constituição argumentativa. Assim, se o Locutor busca contextualizar seus argumentos a partir de um contexto sócio-histórico mais amplo em que ele está inserido, levando-se em consideração a época em que está vivendo, ele busca também usufruir do contexto comunicativo de produção em que o texto é proferido para validar a sua tese a partir de argumentos consistentes e, para isso, ele necessita saber qual o público que está a escutá-lo no embate discursivo, por exemplo.

Como já demonstramos no esquema 1, anteriormente, o plano textual de análise da argumentação é constituído de dois Componentes: Componente Genérico e o Componente Sequencial. Assim, O Componente Genérico englobaria a abordagem desenvolvida por Bakhtin, depois seguida, mesmo que indiretamente, por Maingueneau (2004). Ficou evidente que o pensamento de Bakhtin (1997) se constituiu como um importante arcabouço teórico para a análise dos gêneros do discurso. Assim, seguimos em nossa tese de doutoramento (GARANTIZADO JÚNIOR, 2015) o pensamento desse autor, principalmente por o seu método de trabalho, já presente desde Problemas da Poética de Dostoiévski, em que ele fez uma série de digressões acerca dos gêneros para melhor entender as peculiaridades, naquela oportunidade, ligadas à obra de Dostoiévski, ter se tornando uma importante ferramenta metodológica em vários outros trabalhos. Dessa maneira, acreditamos que a composição dos gêneros é ditada por uma série de articulações composicionais que possibilitam a realização desse gênero nos atos de interação verbal. Concordamos, desse modo, com o aspecto dinâmico que os gêneros ganharam na obra de Bakhtin (1997), que propiciam a estabilidade, sempre estabelecida a partir de relação do gênero com o contexto sócio-histórico em que ele está envolvido.

O Componente Sequencial da argumentação seria constituído pelo plano de texto, pela noção de sequencialidade e pelas esquematizações, todos os conceitos foram encontrados nos achados de Adam $(1992,2008)$ e seguidos no modelo de argumentação sob uma perspectiva textual e retórica em que desenvolvemos. Para isso, elegeram-se os pressupostos de Jean-Michel Adam $(1992,2008)$ que, nas últimas décadas, tem-se desta- 
cado por realizar trabalhos acerca da intersecção entre os aspectos discursivos e textuais, o que ele mesmo chama de aspectos textuais/discursivos. Interessa-nos somente o que o autor descreve como sequencialidade. A abordagem defendida por Adam (1992) propõe a inserção da Linguística Textual no campo da análise de discursos, delimitando o que compete a cada área. Sobre isso, ao se pensar sobre análises, privilegiando os aspectos textuais e discursivos, levando-se em conta também aspectos direcionados aos gêneros, não se "poderia utilizar expressões como frases, períodos, cláusulas ou quaisquer outras sem correr o risco de entrar em outras áreas e se perder em aspectos primeiramente organizacionais" (CATELÃO, 2010).

Em nossa tese de doutoramento (GARANTIZADO JÚNIOR, 2015), em nossas análises, observamos que há um plano de texto que pode conduzir o desenvolvimento de outras estruturas sequenciais em um só texto. Entretanto, na nossa visão, o plano de texto não teria apenas essa utilização, pois ele seria também responsável, por exemplo, pelo entendimento das unidades estruturais que possibilitam fazer com que um sujeito entenda todas as características do gênero textual e, a partir desse entendimento das unidades constitutivas do gênero, que se poderia haver sequências textuais estabelecendo a configuração textual do texto. O indivíduo, quando vai utilizar um determinado gênero, já sabe certos traços que o constituem, como se fossem características globais que, para nós, seriam fruto da configuração do plano do texto que esse sujeito pensa (mesmo que involuntariamente) sobre o gênero que se comunicará concretamente.

$\mathrm{Na}$ verdade, a estrutura composicional dos elementos textuais, seguindo o modelo de Adam (2008), é, inicialmente, ordenada por um plano de texto, base de composição, e, geralmente, categorizável em termos de dominância sequencial. Naquela oportunidade, nosso corpus era constituído de discursos políticos de Sessão Plenária de Deputados do PT e do PSDB sobre o "mensalão". Sob essa ótica, como os textos eram proferidos por um Locutor ocupante do cargo de Legislador, percebemos a dominância da sequência argumentativa, embora saibamos que outras sequências eram inseridas na argumentação dos Locutores.

Para nós, outro elemento que constitui o Componente Sequencial seria a formação de esquematizações construída a partir das sequências textuais, o que desencadeia, diretamente, Pontos de Vistas (PdV) diversificados do Locutor. Esses conceitos foram tratados por Adam (2005), quando ele propõe que o processo de esquematização discursiva é um dos elementos que constituem a composição textual. Em Garantizado Júnior (2015), a partir dos achados de Adam (2005) e de Catelão (2010), optou-se pela análise mais aprofundada das esquematizações discursivas e da construção dos PdV do Locutor, a fim de propiciar o quadro retórico (uma lista de possibilidades de argumentos viáveis e não viáveis em que o Locutor, por meio das estruturas composcionais do texto, projetava-se em forma de construir a sua melhor imagem sobre o que é abordado na prática discursiva). $\mathrm{O}$ que ficou evidente é que o Componente Sequencial, visto sob o prisma defendido por nós (GARANTIZADO JÚNIOR, 2015), possibilita uma estreita relação entre o Componente Textual e o Componente Retórico. Isso se dá pelas construções de argumentos constituídas pelo PdV e que, de alguma maneira, projetam-se no éthos, páthos e lógos (elementos que constituem o Componente Retórico).

A possibilidade de análise do texto, seguindo o que demonstrara Adam (2008), para nós, seria a possibilidade de se poder decompor o texto em planos composicionais e discursivos. Para que isso fosse realizado com exatidão e eficácia, deve-se ter uma abordagem em que se possa estabelecer a relação de conceitos inerentes a toda proposição -enunciado, que, segundo Adam (2008), seriam indispensáveis na observação dos dados 
em um estudo mais aprofundado. Por causa disso, ele defende a impossibilidade de existirem enunciados desprovidos de uma responsabilidade enunciativa $-\mathrm{PdV}-$ (ponto de vista enunciativo marcado por um grau de responsabilidade- Podem aparecer marcadas com índices de pessoas (meu, teu); dêiticos espaciais e temporais; tempos verbais, entre outros). A responsabilidade enunciativa ou fonte do saber implementa qualquer análise à medida que vislumbra a quem pertence o ponto de vista enunciado - PdV. É pertinente explicar que o PdV pode ser encarado como o processo de engajamento em que o Locutor possui com o seu texto, tanto que Adam (2008), para explicar esse conceito, recorre aos aspectos pragmáticos dos atos de fala.

$\mathrm{O}$ mais das vezes, o grau de PdV é claramente marcado em unidades da língua, seja por expressões que claramente definem o PdV (de acordo, segundo, para), ou por expressões que assinalam um PdV anônimo (parece). Para ele, além da responsabilidade enunciativa, os discursos comportam uma referência como representação discursiva (Rd) construída pelo conteúdo proposicional (ponto de vista semântico, tema, objeto de discurso, predicação). Para Catelão (2010), a Rd seria o sentido atribuído aos enunciados em relação ao mundo e às condições de recepção (as perguntas: quem? o quê? quando? por quê? e como?) a ele circundados e que contribuem para o reconhecimento da situação de produção, ocorrência e recorrência da situação ou de partes dela.

Em nossa tese de doutoramento (GARANTIZADO JÚNIOR, 2015), o conceito de esquematização discursiva é usado em razão das particularidades discursivas dos textos e de sua própria materialidade. Essa importante noção tem como princípio que qualquer atividade discursiva é originária de uma esquematização, a qual tem por propriedade aliar em um mesmo plano o enunciado como processo e como resultado, ou seja, o enunciado como fruto da escolha do Locutor para atender a determinado sentido e como resultado do sentido atribuído pelo interlocutor no momento de recepção do discurso. Desse modo, a esquematização abrange duas ações:

1. o processo (ação desempenhada pelo autor, sujeito no mundo, de construção de uma esquematização e de uma imagem de éthos nessa esquematização) e

2. o resultado (um discurso que propicia por parte do coenunciador uma interpretação, reesquematização e visualização do éthos) de um discurso, inseparável de uma memória intertextual/interdiscursiva que compreende a consideração não só do enunciado em si, como de toda expressão dialógica que ele comporta.

Na nossa visão de análise e descrição da argumentação, o Componente Retórico da argumentação é constituído de dois importantes aspectos: a) as estratégias argumentativas capazes de provar os argumentos do Locutor (PERELMAN; TYTECA, 1996) e b) das projeções do éthos, páthos e logos (AMOSSY, 2011). Na verdade, o que estamos chamando de Componente Retórico diz respeito às investidas do Locutor em tentar apresentar-se para o seu auditório a partir da construção de uma imagem positiva de si, além das técnicas de persuasão. Nos textos de cunho argumentativo, encontramos essa busca de construir uma imagem, mesmo esta sendo involuntária. Desse modo, o éthos, como já preconizava Aristóteles em sua Retórica, assim como o éthos defendido por Amossy (2011), ganham destaque em nosso modelo. Outrossim, estudar a argumentação sem considerar essa importante "artimanha discursiva" para a construção da persuasão seria negligenciar o papel das técnicas argumentativas que o Locutor usa para chegar aos seus objetivos no ato argumentativo. 
$\mathrm{Na}$ Retórica, éthos, péthos e lógos constituem a tríplice dimensão da disciplina. $\mathrm{Na}$ verdade, o éthos é aquele fenômeno/procedimento capaz, de certa forma, de responder por intermédio do lógos a uma série de questões sobre as quais o ser humano negocia aproximações e distanciamentos diversos. Acerca disso, Mosca (1997) nos diz que os enunciados são produto de estratégias que levam em conta tensões entre os interlocutores, a manutenção do equilíbrio, a continuidade da relação entre eles, para que a negociação entre as partes possa ser estabelecida. Nesse sentido, o éthos é uma excelência que não tem objetivo próprio, mas se liga à pessoa, à imagem que o Locutor passa de si mesmo, o que o torna exemplar aos olhos do auditório, que então se dispõe a ouvi-lo e a segui-lo. Nota-se a importância do éthos por possibilitar estabelecer um grau de confiabilidade no Locutor no momento do ato persuasivo.

Quando o Locutor toma a palavra com o objetivo de tentar persuadir o seu auditório, aquele necessita construir uma imagem para este poder ser convencido. Em muitas situações, essa construção dá-se de forma involuntária; em outras, proposital. O certo é que, em todas elas, a imagem do Locutor é construída e, sempre, com objetivos bastante claros: persuadir seus pares. Assim, o Locutor busca apresentar-se positivamente; desde uma simples conversa com amigos até uma conferência, sua imagem está em constante evidência.

Na verdade, o que se observa é que, segundo Catelão (2013), a imagem do "eu" no discurso é criada por meio de figuras que são acionadas entre um participante que fala/ escreve e outro que recebe, decodifica, compreende, interpreta e tem a chance de posicionar-se por outra figura de retorno. De um ponto de vista geral, essas figuras são geradas de acordo com as funções sociais dos indivíduos participantes da situação de produção, segundo determinados comportamentos humanos que acabam por configurar e se cristalizar em determinadas "figuras-tipo" ou de identidades, que vão se reinventando e reaparecendo de acordo com o ambiente, a época e a situação em que são adotadas. Elas ficam expressas no "poder das palavras", legitimadas pelo responsável pelo que é dito e firmadas por certos estereótipos sociais, como a mãe de família, o homem de Deus, o político corrupto, dentre tantas outras possibilidades de projeções.

Em nosso modelo (GARANTIZADO JÚNIOR, 2015), a projeção do éthos, do páthos e do lógos será importante, principalmente a projeção do éthos, pois usaremos esses conceitos seguindo o que Adam (2005) preconiza como esquematizações discursivas. $\mathrm{Na}$ verdade, o autor busca apresentar um modelo que dê conta de estabelecer uma projeção dessas noções e, para isso, ele defende que as estruturas composicionais dizem respeito ao processo de esquematização discursiva que, em outro nível, permite aliar dados do ponto de vista, representação discursiva e valor ilocucionário, por meio da caracterização da situação sociodiscursiva, da condição de produção e da condição de recepção do discurso. Observamos, desse modo, que o autor considera o contexto externo ao texto, assim como o ponto de vista $(\mathrm{PdV})$ que um Locutor estabelece no ato comunicativo. Esse conceito é importante em nosso modelo teórico, pois temos, em muitos momentos, nas tentativas de argumentação do Locutor, a construção de posicionamentos sendo construídos.

O Componente Retórico constitui-se do éthos como elemento responsável pela projeção dos sujeitos envolvidos no ato comunicativo, assim como do próprio assunto a ser tratado, como já preconizava a Retórica dos antigos. No entanto, essas noções, para que os objetivos sejam concretizados, necessitam de técnicas mais apuradas para alcançarem os seus objetivos. Desse modo, o Componente Retórico contará com a integração de conceitos da Retórica e Nova Retórica no que se refere ao acordo e ao estabelecimento do discurso frente aos tipos de argumento, ou seja, "beberemos da fonte" aristotélica, assim como da de Perelman e Tyteca (1996). Estes desenvolveram uma típica teoria centrada no auditório, ou seja, naqueles 
cuja adesão se visa ganhar, e, por esta razão, a relação com a Retórica (principalmente a desenvolvida por Aristóteles) é bastante estreita. Na verdade, o argumentar estaria diretamente relacionado com o ato de participar de uma argumentação, de modo que o orador possa fornecer argumentos, razões, a favor, ou até mesmo contrárias, a uma determinada tese.

A Nova Retórica tem uma íntima ligação com a retórica clássica, embora Perelman e Tyteca (1996) promovam algumas mudanças, o que justifica o adjetivo "Nova". De fato, a Nova Retórica retoma parte do pensamento clássico, mas promove alguns avanços. Consideramos que o modelo proposto está associado diretamente à arte do falar bem, ou mais do que isso em alguns momentos, já que ela está voltada para a forma de falar e de conseguir um efeito esperado. Nessa nova realidade de lidar com a argumentação, a Nova Retórica dispensa o discurso falado informal e vai em busca de um discurso mais elaborado quanto às múltiplas possibilidades de aspectos lógicos, valorizando as razões, os convencimentos e, com certeza, motivando o estudo da persuasão. Assim, busca-se estudar todos os tipos de auditórios, não se restringindo a nenhum, podendo ter desde um auditório mais leigo sobre o assunto proposto pelo Locutor até um mais competente.

Após todos esses esclarecimentos teóricos sobre o nosso modelo de análise da argumentação, é fulcral a aplicação de nossa proposta em diversificadas situações em que um Locutor busque a "adesão dos espíritos" (PERELMAN; TYTECA, 1996) de um auditório. Assim, a carta-testamento de Getúlio Vargas, enquanto objeto analítico, pode servir para refletirmos como o nosso modelo se enquadra com outras situações comunicativas complexas e que envolvam práticas discursivas. Nesse sentido, na próxima seção, passemos para a descrição analítica de nosso modelo, tomando-se como base os aspectos de produção do texto, assim como os aspetos composicionais e retóricos que o transformaram em um dos principais documentos da História recente brasileira.

\section{Análise dos aspectos argumentativos da Carta-Testamento de Getúlio Vargas}

Como demonstramos na seção anterior, a argumentação pode ser analisada também a partir dos aspectos externos ao texto. Levando-se em consideração nossas categorias de análise, podemos indicar que as condições de produção sócio-históricas da Carta-Testamento do presidente Getúlio Vargas representavam uma época de muita rivalidade entre os que defendiam a continuidade do "projeto político" da Era Vargas e os que queriam a constituição de uma retomada de poder, nem que fosse preciso retirar o presidente do cargo por meio de um golpe. Aos poucos, a opinião pública e as forças políticas, antes vitais para a manutenção do governo de Vargas, tornaram-se instrumentos que configuraram a sua diminuição da popularidade, dificultando o diálogo do Locutor com o seu interlocutor principal: o povo. Desse modo, essa ruptura entre presidente e o povo ruiu algo vital em seu governo característico por práticas populistas: a opinião pública favorável ao governo. A época estava indicativa para várias pressões, que viam desde o plano interno (forças políticas e opositores ao governo), até forças externas (o mercado externo revoltado pelas imposições e intromissões governamentais do presidente na economia, como foi o caso da criação de órgãos sem a participação de investimentos externos e controlados pelo Estado, como a Petrobrás). Isso ficou claro no trecho a seguir, da Carta-Testamento:

Mais uma vez, as forças e os interesses contra o povo coordenaram-se e novamente se desencadeiam sobre mim. Não me acusam, insultam; não me combatem, caluniam, e não me dão o direito de defesa. Precisam sufocar a minha voz e impedir a minha ação, para que eu não continue a defender, como sempre defendi, o povo e principalmente os humildes (CARTA-TESTAMENTO). 
Como se pode perceber, "as forças" e "os interesses contra o povo" reforçam a ideia de que o presidente estava passando por uma situação complicada em seu governo. Essas "forças" indicam um argumento de que o presidente sofre forças ocultas (a posição? O mercado externo?) que, de maneira direta, implicavam um argumento de que "as forças estão contra o povo". Como se pode perceber, o contexto amplo em que o Locutor Getúlio Vargas está inserido é determinante para o processo de construção das perspectivas argumentativas que o projetam como "preocupado com a população" e como "não possui direito de defesa". A expressão "precisam sufocar a minha voz" é indicativa de que "buscam" (várias forças) retirar o governante com o propósito nítido: um golpe governamental.

A situação específica em que o texto é produzido é muito duvidosa. Muitos ainda questionam a veracidade do documento oficial, mas, como apresentamos na introdução deste trabalho, não entraremos nessa questão e, desse modo, nosso foco será apenas a análise do texto lido para a população após o ato de suicídio do presidente. Ao que parece, essas "forças" indicadas no trecho da carta proporcionaram um fato bastante relevante: o Locutor preferiu o suicídio a perder seu governo. O que chama atenção é que, em outro momento da História, o Locutor já havia passado por problemas semelhantes e a solução, naquela oportunidade, foi renunciar, como ficou evidente na passagem "iniciei o trabalho de libertação e instaurei o regime de liberdade social. Tive de renunciar. Voltei ao governo nos braços do povo". Catelão (2010), quando analisou cartas de suicidas, a fim de demonstrar os impactos argumentativos envolvidos, percebeu que o argumento de "algo proporciona o ato" foi bastante recorrente. O ato "suicida" do presidente, de certa forma, foi eivado de projeções de "culpa de outros" para a realização do ato. Na verdade, aparentemente, o Locutor do texto quer argumentar os motivos pelos quais o fizeram cometer a ação de perder a vida completamente. Essa constituição foi notada no trecho:

Sigo o destino que me é imposto. Depois de decênios de domínio e espoliação dos grupos econômicos e financeiros internacionais, fiz-me chefe de uma revolução e venci. Iniciei o trabalho de libertação e instaurei o regime de liberdade social (CARTA-TESTAMENTO).

Como se pode perceber, o Locutor reconhece que possui um "destino" que lhe é "imposto", como que justificando a ação de suicídio que cometerá. O que se evidencia é que o Locutor, movido pelas ações de interferências externas, busca a retirada da vida com um propósito determinado. A indicação de que a época em que ele governava era complicada se confirma com "fiz-me chefe de uma revolução e venci". O item lexical "destino" é muito elucidativo na justificativa de que o suicídio deveria ser feito, era algo imposto e que seria a única saída do Locutor, a fim de preservar e defender a população.

Esses aspectos externos condicionam coerções para a produção do gênero Carta-Testamento. A definição de gênero defendida por nosso trabalho tem como influência os achados de Bakhtin (1997) acerca dessa fundamental noção teórica para os estudos da linguagem. Desse modo, entendemos que o gênero é um construto abstrato com características relativamente estáveis, inseridas em um contexto sócio-histórico de produção comunicativa e que se manifesta, de maneira material, por meio de textos que, necessariamente, necessitam de contextos de usos concretos.

Seguindo as ideias de Bakhtin (1997), as unidades temáticas que se constituem no texto são sempre relacionadas ao processo de significação amplo em que indica a derrubada do poder do presidente por outras forças não mencionadas pela carta, mas que se apresentam de forma recorrente pela repetição de estruturas lexicais que nos faz perceber 
que o tema "forças" se faz presente. A ideia central do texto é o fato de um Locutor cometer suicídio e, assim, não deixar uma "carta de suicídio", mas uma "Carta-Testamento", como se o texto indicasse o legado deixado por ele para a população, já que a palavra testamento indica bens destinados a outro sujeito.

Outro elemento importante na constituição do Componente Genérico é o estilo. Como se pode perceber, em muitos momentos, o Locutor opta por termos que demonstram uma ação positiva de suas medidas governamentais, como em "não querem que o povo seja independente" ou em "cada gota de meu sangue será uma chama imortal na vossa consciência e manterá a vibração sagrada para a resistência. Ao ódio respondo com o perdão". Na primeira passagem, a palavra "independente", usada pelo Locutor, fora propositalmente uma forma de indicar que a ação de suicídio se dava, principalmente, por ele não conseguir combater ações externas contra o seu governo. Diretamente, percebemos a "incitação" do povo contra os "que queria a queda" do Locutor, como se o suicídio fosse o único caminho e, por saber disso, o presidente tendenciava a jogar a população (que estava contra ele naquele momento) contra os que queriam um golpe. O estilo também foi notado na expressão "sangue", que aparece algumas vezes no texto, fazendo referência direta ao ato cometido e, assim, chamando o interlocutor a entender os motivos da ação suicida. O Locutor, ao indicar que "cada gota de sangue" constituirá uma "chama imortal" capaz de produzir sujeitos resistentes, indica o quão é necessário o "combate às forças" que o proporcionaram ao ato. Nota-se, desse modo, que há uma nítida construção de uma argumentação que induz a população a se revoltar contra os opositores do governo. Aparentemente, o Locutor, ao jogar a culpa da ação em um outrem, transfere as suas ações de culpa e fraqueza para responsabilizar os que lhe motivaram a fazer isso, o que acaba construindo outro argumento: "não havia mais o que fazer a não ser o suicídio".

Analisando os aspectos relacionados ao Componente Sequencial, percebemos que o texto, para construir o seu todo argumentativo e significativo, precisa que seja encadeado em subconjuntos das partes que o forma. A sequenciação do plano do texto acontece em uma sucessão. Assim sendo, o texto é construído de partes, que, por sua vez, constrói uma unidade de sentido e se realiza em um contexto, designada por Adam (2008) como uma unidade semântica e pragmática denominada "configuracional", porque nela estão inclusas as partes do enunciado que forma o todo do texto. Na Carta-Testamento, a predominância da sequência argumentativa se dá por causa da busca do Locutor em indicar uma argumentação de que "fez o ato em prol do Brasil" e de que "forças o conduziram a tomar a atitude de suicídio". Entretanto, percebemos a sequência narrativa no segundo e no terceiro parágrafo do texto. Isso se confirma, principalmente, nos verbos usados com tempo indicativo de passado. Mesmo assim, apesar da tentativa de narrar procedimentos e fatos já ocorridos, o Locutor as usam com o propósito argumentativo: convencer a população de que o suicídio era o melhor caminho e que a oposição não deve chegar ao poder após sua morte.

Obviamente, pensar em argumentação é entender que o Locutor, mesmo que involuntariamente, faz uso das características condicionadas socialmente para os gêneros e, assim, usam-nas de forma a tentar demonstrar que seus argumentos são convincentes. Deve-se, portanto, entender que, no caso do Locutor em questão, isso não ocorre, pois ele busca convencer a população brasileira sobre os motivos reais que o levaram à morte. Por causa disso, o plano do texto da Carta-Testamento tem como elemento importante a apresentação da temática a ser abordada em forma de uma ponderação problemática, que se instaura por meio de uma relação dialógica e intertextual os fatos que aconteceram no atentado na Rua Tonelero e nas ações do governo apresentadas por Getúlio no texto. 
O texto em destaque, com certeza, tem como característica principal a persuasão. Quando se pensa em um discurso proferido por um Locutor em uma situação de comunicação com contexto político complicado, pensa-se nas intenções desse sujeito em empreender sua tese e seu ponto de vista em relação a um determinado público. Desse modo, o gênero Carta-Testamento, além de sofrer coerções da situação comunicativa em que o sujeito está inserido, também condiciona, por exemplo, as escolhas lexicais, com o fito de se ter as estratégias argumentativas sendo bem apresentadas. As palavras "sangue", "forças", "humilhar" ou expressões como "me liberto", "saio dessa vida", "campanha subterrânea", dentre outras, indicam a projeção de um éthos de "não culpa" e "presidente preocupado com a população humilde" no Locutor. Importante, também, que possamos estabelecer os limites estabelecidos pelas proposições-enunciados apresentadas no texto refletindo a situação de comunicação. Isso é oportuno antes de mostrarmos o esquema de sequencialidade que se constitui nos dois textos em análise. Assim, o ponto de vista (PDV), a representação discursiva $(\mathrm{RD})$ e os valores ilocucionários são coocorrentes no texto em análise.

Com relação ao PdV desenvolvido, percebemos que ele está apresentado significativamente marcado em torno da necessidade de apresentar que existiu uma "força" contrária ao governo, momento em que o Locutor se engaja a seu enunciado. Isso aparece nitidamente em vários momentos do texto e é sobre o ponto de vista da existência "dessas forças" e de que a "os mais humildes serão desamparados" que se fundamentou o PdV de que "o suicídio é fruto dessas forças" e de que o Locutor "lutou contra a espoliação do povo". Nesse sentido, constrói-se uma representação discursiva (RD) para o discurso e dela se possibilita a criação de um éthos em que uma imagem de si emblemática de que "Getúlio, pai dos pobres" se projeta. Na realidade, o PdV que se constrói na imagem do Locutor é a de engajamento com o que está sendo proferido, o que nos permite indicar que há uma forte busca em valorizar os aspectos positivos do presidente, assim como as ações empreendidas em seu mandato. Isso se confirma nas diversas passagens em que o argumento de "salvados dos pobres" se expressa.

A leitura do texto nos possibilita indicar os seguintes argumentos centrais: a) as forças externas ao governo impossibilitam o Locutor de exercer seu trabalho corretamente em favor dos pobres; b) a população brasileira, com a morte do Locutor, ficará desamparada e c) O Locutor não tem culpa pelo seu ato em prol do povo, pois ele deixa a vida para entra na História em função da preocupação dele com o povo. Essa base de argumentos nos possibilita a construir a organização composicional da sequência argumentativa, uma das ações possíveis para o Componente Sequencial.

No texto em destaque, usando o quadro proposto por Adam (1992), podemos dizer que o P. arg. 0 pode ser considerado o fato de o Locutor querer justificar os motivos de fazer o ato de suicídio. A tese inicial do texto seria apresentar justamente a defesa de seu governo e de suas ações em prol da população. Interessante é que a tese inicial, de certa forma, não aparece no início do texto, mas fragmentada em algumas partes no segundo parágrafo.

De forma indireta, o discurso do Locutor se constitui de premissas (P. arg 1) calcadas nas informações de que o seu desejo era a continuidade de ações que privilegiavam a população, que se sustenta como argumento quase que central na composição textual. Para manifestar esse pensamento em forma de argumento, o Locutor usa alguns procedimentos, que ele chama de "questões":

1. "Precisam sufocar a minha voz e impedir a minha ação, para que eu não continue a defender, como sempre defendi, o povo e principalmente os humildes". Nesse 
argumento apresentado pelo Locutor, notamos claramente que ele busca destacar o quanto foi o "pai dos pobres" e que "tentou sempre os caminhos para os mais humildes". Esse argumento só surte efeito, isto é, só leva à conclusão pretendida, se os interlocutores o ancorarem em certas inferências (ancoragem inferencial - P. arg 1), como no conhecimento de mundo que o presidente fez ações pelas quais desagradaram "forças" que o fazem cometer o suicídio em prol da população. É essa ancoragem de inferências que permite chegar à conclusão de que a oposição e as forças de capital estrangeiro tentam de todas as maneiras convencerem a sociedade de que Getúlio faz um péssimo governo;

2. “Meu sacrifício vos manterá unidos e meu nome será a vossa bandeira de luta. Cada gota de meu sangue será uma chama imortal na vossa consciência e manterá a vibração sagrada para a resistência. Ao ódio respondo com o perdão”. Esse argumento também pode ser enquadrado na construção argumentativa como (P. arg 1), uma vez que se configura como uma informação dada em busca de apresentar a confirmação da tese (Getúlio está cometendo suicídio para salvar os pobres e por ter forças externas contra o seu governo). Para empreender esse argumento, o Locutor usa de estratégias argumentativas de "politizar" a decisão do suicídio, argumentando a favor de seu ato de "fim da vida" como única saída para que as "forças" não cheguem ao poder.

No desenvolvimento da sequência argumentativa do texto, o elemento de restrição (P. arg 4) aparece explicitamente (sabemos que nem sempre as afirmações são contraditadas explicitamente nos textos), mas também exigem os conhecimentos de mundo dos que integram o auditório. Assim, observemos o trecho da carta:

Tenho lutado mês a mês, dia a dia, hora a hora, resistindo a uma pressão constante, incessante, tudo suportando em silêncio, tudo esquecendo, renunciando a mim mesmo, para defender o povo, que agora se queda desamparado. Nada mais vos posso dar, a não ser meu sangue (CARTA-TESTAMENTO).

De forma implícita, o Locutor afirma a sua luta contra as ações da oposição, indicando que o povo estava sendo levado a um ato falho ao querer a "saída de Getúlio da preseidência", já que este "apenas queria o bem comum dos pobres". Podemos considerar que essa restrição também ocorreu na expressão "não querem que o povo seja independente", que seria uma restrição em forma de argumento contra o que estava sendo falado anteriormente.

$\mathrm{O}$ argumento conclusivo (P. arg 3) pode ser considerado a seguinte passagem:

Lutei contra a espoliação do Brasil. Lutei contra a espoliação do povo. Tenho lutado de peito aberto. O ódio, as infâmias, a calúnia não abateram meu ânimo. Eu vos dei a minha vida. Agora vos ofereço a minha morte. Nada receio. Serenamente dou o primeiro passo no caminho da eternidade e saio da vida para entrar na História (CARTA-TESTAMENTO).

Observe-se que esse argumento retoma a tese central, mas se configura como uma nova tese, ao propor que o Locutor "saiu da vida para entrar na História". Toda essa estrutura sequencial argumentativa proporciona que se condicione uma série de esquematizações que, de certa forma, projetam-se no éthos do Locutor.

Sendo assim, O Componente Retórico se constitui a partir das projeções das imagens do Locutor Getúlio Vargas faz de si. Mantendo-se essa linha de raciocínio, o éthos do 
Locutor constrói-se na apresentação de suas qualidades, o que nos faz entender a projeção da imagem positiva do político Getúlio. O sujeito apresenta-se como um "pai dos pobres" e que "está preocupado com os humildes". Essas projeções são transpostas, em muitos momentos, ao longo da Carta-Testamento. A leitura desse texto nos faz entender que o éthos que se apresenta pelo Locutor é o de "injustiça" e "altruísmo", já que o Locutor empreende a construção de uma imagem de que as "forças" que o impedem de proporcionar transformações sociais. Nesse sentido, a Carta-Testamento constitui-se de uma justificativa para a população sobre o ato de suicídio, em prol de impossibilitar que as forças contrárias ao Locutor tomassem o poder.

A projeção do éthos de "perseguição política" é constante ao longo do texto. Na verdade, o alicerce da argumentatividade do Locutor é em indicar o quão complicado estava sendo governar o país com a oposição jogando o povo contra o governo. Assim, o éthos de "pai dos pobres" e o de "pai dos humildes" projeta-se como uma solução para cativar o interlocutor (leitores da carta) sobre o momento conturbado. Esse argumento de que "forças externas" ao governo impossibilitavam as transformações e as melhorias sociais impostas pelo Locutor é o principal argumento para tentar ter a "adesão do auditório" (PERELMAN; TYTECA, 1996). Aparentemente, o motivo da Carta é o de indicar o quão estava complicado a governabilidade e, assim, o suicídio já seria um “destino" que o Locutor deveria cumprir. O éthos de "salvador" também se projeta ao longo da carta, quando o Locutor busca indicar que sua morte representaria um sacrifício para que as "forças" não conquistassem o poder. A imagem que se forma do Locutor é o de preocupado com a população, com os humilhados e com os excluídos.

Ademais, O éthos de "justiceiro" é empreendido pelo Locutor como se ele quisesse demonstrar as incoerências da época política em que ele estava vivenciando. A imagem que se apresenta é de um político preocupado com o fato de "forças externas" o perseguirem e não possibilitarem as transformações sociais e econômicas iniciadas pelo seu governo. Nesse sentido, o Locutor advoga para o argumento de "Querem calar a minha voz" para se projetar com um éthos de "suicídio para não tomarem o poder". A imagem que se desenvolve desse Locutor, contrapondo-se ao do Locutor de oposição, é de "injustiça", sob a alegação de "manobra política", já que não há "contraprovas", logo foi feito um "momento em que a sua morte é necessária".

Para que essas projeções ocorressem de maneira eficiente, muitas técnicas foram usadas pelo Locutor propositalmente, a fim de justificar sua decisão pelo suicídio e, principalmente, jogar a população contra os seus opositores após o ato de "perda da vida". Devido à quantidade muito vasta de técnicas presentes na Nova Retórica, neste trabalho, apresentaremos apenas as mais significativas para a construção da projeção do éthos de "pai dos pobres" e que, de alguma maneira, confirme a tese inicial da sequência argumentativa. Desse modo, fica a dica para que esse importante documento possa ser analisado sob o olhar das várias estratégias argumentativas.

Sendo assim, um dos argumentos muito notórios foi o que se baseia na estrutura da realidade (PERELMAN; TYTECA, 1996), que são aqueles ancorados nas relações de nosso sistema de significados a partir do mundo objetivo. Um dos mais notados foi o argumento de causalidade, em que se argumenta e se expõe a causa dos fenômenos. Como se sabe, uma causa se impõe por uma série de encadeamento dos fatos, o que podemos observar em "A campanha subterrânea dos grupos internacionais aliou-se à dos grupos nacionais revoltados contra o regime de garantia do trabalho", em que o Locutor usa a força da oposição como uma das causas do ato suicida por ele realizado. Na verdade, esse 
argumento se apresenta com uma multiplicidade de causas, que seriam outras possibilidades que podem constituir a projeção do éthos de "injustiça", como em "não querem que o povo seja independente. Assumi o Governo dentro da espiral inflacionária que destruía os valores do trabalho. Os lucros das empresas estrangeiras alcançavam até 500\% ao ano", em que se projeta outra possibilidade de causa para o ato cometido.

Outro argumento muito utilizado pelo Locutor foi o de "argumento do sacrifício". Para Perelman e Tyteca (1996), esse tipo de técnica seria um tipo de argumento que se aproxima com o da comparação e que busca comprovar a veracidade de uma tese pelo sacrifício de alguém que tem alguma pureza de propósito. No caso do Locutor da Carta-Testamento, a projeção do éthos de "altruísmo" se deu por meio das técnicas do argumento de sacrifício. Argumentos como "como sempre defendi, o povo e principalmente os humildes", "Iniciei o trabalho de libertação e instaurei o regime de liberdade social. Tive de renunciar", "Meu sacrifício vos manterá unidos e meu nome será a vossa bandeira de luta. Cada gota de meu sangue será uma chama imortal na vossa consciência e manterá a vibração sagrada para a resistência" e "Eu vos dei a minha vida. Agora vos ofereço a minha morte. Nada receio. Serenamente dou o primeiro passo no caminho da eternidade e saio da vida para entrar na História". Nos três trechos apresentados da Carta-Testamento, o que se observa é um Locutor que se projeta como "capaz de fazer sacrifícios pelo povo brasileiro". Esse argumento é confirmado pela presença de itens lexicais que, em termos semânticos, aproximam-se dessa noção altruísta de forma explícita (como é o caso do uso da palavra "sacrifício" no segundo argumento) e implícita (palavras como "sangue", "renunciar" e "defendi”, por exemplo). É evidente que essa base de argumento confirma a projeção de um éthos positivo do Locutor, capaz de "cometer o suicídio em prol da população mais humilde" ou "cometer o suicídio só para não deixar que as forças externas cheguem ao poder”.

\section{Considerações finais}

Como se demonstrou, o modelo de argumentação sob um prisma textual e retórico, considerando aspectos externos ao texto como a época e a situação comunicativa, pode servir para explicar a construção da argumentação em textos de natureza argumentativa, como é o caso da Carta-Testamento do presidente Getúlio Vargas. Ademais, demonstramos que os três planos de descrição e análise da argumentação podem ser úteis no processo de investigação de textos verbais.

Ficou evidente que os Elementos externos ao texto foram fatores cruciais e determinantes para a confecção do texto histórico de Getúlio Vargas, já que as condições sócio -históricas de produção em que o Locutor estava inserido, de muita instabilidade política, além da situação comunicativa em que o texto fora produzido, com o presidente prestes a ser deposto de seu cargo, condicionaram um texto eivado de passagens que valorizaram a sua imagem de o "pai dos pobres", que fora comprovada nas esquematizações e no Ponto de Vista (PdV) dos argumentos elencados pelo Locutor ao longo do Componente Sequencial e Componente Genérico e, assim, imprimiram a tese de que "o suicídio era o único caminho", pois "forças externas contrárias às ações que beneficiavam o povo" queriam tirar o presidente do governo.

Nesse contexto, fica a sugestão de que outros trabalhos possam utilizar a aplicabilidade do modelo, investigando a sua exatidão na análise da construção da argumentação. Nesse sentido, o grande desafio seria observar em que outras práticas discursivas a teoria pode proporcionar descrição de aspectos argumentativos. 
ADAM, Jean-Michel. Les textes: types et prototypes. Paris: Nathan, 1992. . Imagens de si e esquematização do orador: Pétain e De Gaulle em junho de

1940. In: AMOSSY, Ruth. Imagens de si no discurso: a construção do ethos. São Paulo: Editora Contexto, 2005, p.93-117. . A linguística Textual: Introdução à análise textual dos discursos. Tradução:

Maria das Graças Soares Rodrigues et. al. São Paulo: Cortez, 2008.

AMOSSY, Ruth. Imagens de si no discurso: a construção do éthos. São Paulo: Editora Contexto, 2011.

ARISTÓTELES. Topiques. Tme I. Livres I-IV. Tradução e introdução de Jacques Brunschwig. Paris: Les Belles Lettres, 1967.

. La Métaphysique. Tome I. Tradução, introdução e notas de J. Tricot. Paris: J.

Vrin, 1986.

Vrin, 1987.

Éthique à Nicomaque. Tradução, introdução e notas de J. Tricot. 6 ed. Paris: J.

Retórica. São Paulo: Edipro, 2011.

BAKHTIN, Mikhail. Estética da criação verbal. Trad. Maria Ermantina Galvão G.

Pereira. 2a. Ed. São Paulo: Martins Fontes, 1997.

CATELÃO, Evandro de Melo. Textos argumentativos sob a ótica sociodiscursiva JeanMichel Adam: primeiras aproximações. In: Anais do IX Encontro do CELSUL Palhoça, SC: Universidade do Sul de Santa Catarina, 2010.

- Revelando motivos: a argumentação de suicidas sob as perspectivas textual/discursiva e retórica. Tese (doutorado). Universidade Federal de Santa Catarina, Curitiba: 2013. CHARAUDEAU, Patrick. Langage et Discours: Eléments de sémiolinguistique. Paris: Hachette-Université, 1983. . Grammaire du sens et de l'expression. Paris: Hachette, 1992. . Le contrat de communication de l'information médiatique. Paris: Hachette Juillet, 1994.

MAINGUENEAU, Dominique. Análise de textos de comunicação. São Paulo: Cortez, 2004.

MOSCA, Lineide do Lago Salvador. Velhas e Novas Retóricas: convergência e desdobramentos. In: MOSCA, Lineide do Lago Salvador, (Org.) Retóricas de Ontem e de Hoje. São Paulo: Humanitas Editora FFLCH/ USP, 1997.

PERELMAN, Chaïm; OLBRECHTS-TYTECA, Lucie. Tratado da argumentação: a nova retórica. Trad. Maria Ermantina de Almeida Prado Galvão. São Paulo: Martins Fontes, 1996.

PINTO, Rosalice. Como argumentar e persuadir? práticas políticas, jurídicas e jornalísticas. Lisboa: Quid Juris, 2010.

GARANTIZADO JÚNIOR, José Olavo da Silva. Estudo da argumentação sob uma perspectiva textual e retórica. Tese (Doutorado)- Universidade Federal do Ceará, Centro de Humanidades, Departamento de Letras Vernáculas, Programa de Pós-Graduação em Linguística, Fortaleza: 2015. 